\title{
Conventional and atom transfer radical copolymerization of phenoxycarbonylmethyl methacrylate-styrene and thermal behavior of their copolymers
}

\author{
G. Barim, K. Demirelli*, M. Coşkun \\ University of Firat, Faculty of Science and Arts, Department of Chemistry, 23119 Elazig, Turkey
}

Received 19 February 2007; accepted in revised form 5 July 2007

\begin{abstract}
The atom transfer radical polymerization (ATRP) of phenoxycarbonylmethyl methacrylate (PCMMA) with styrene $(\mathrm{St})$ were performed in bulk at $110^{\circ} \mathrm{C}$ in the presence of ethyl 2-bromoacetate, cuprous(I)bromide $(\mathrm{CuBr})$, and N,N,N',N",N"-pentamethyldiethyltriamine. Also, a series conventional free-radical polymerization (CFRP) of PCMMA and styrene were carried out in the presence of $2,2^{\prime}$-azobisisobutyronitrile in 1,4-dioxane solvent at $60^{\circ} \mathrm{C}$. The structure of homo and copolymers was characterized by IR, ${ }^{1} \mathrm{H}$ and ${ }^{13} \mathrm{C}-\mathrm{NMR}$ techniques. The composition of the copolymers was calculated by ${ }^{1} \mathrm{H}-\mathrm{NMR}$ spectra. The average-molecular weight of the copolymers were investigated by Gel Permeation Chromatography (GPC). For copolymerization system, their monomer reactivity ratios were obtained by using both Kelen-Tüdős and Fineman-Ross equations. Thermal analysis measurements of homo- and copolymers prepared CFRP and ATRP methods were measured by TGA-50 and DSC-50. Blends of poly(PCMMA) and poly(St) obtained via ATRP method have been prepared by casting films from dichlorormethane solution. The blends were characterized by differential scanning calorimetry. The initial decomposition temperatures of the resulting copolymers increased with increasing mole fraction of St.
\end{abstract}

Keywords: polymer synthesis, molecular engineering, polymer composites, thermal properties

\section{Introduction}

Controlled/living vinyl addition polymerization giving a wide range of polymer structures is continuing to receive widespread attention [1]. This allows the controlled synthesis of a range of polymeric structures such as block copolymers, graft copolymers, functional polymes, star polymers $[2$, $3]$. In comparison to the other controlled radical polymerization processes, atom transfer radical polymerizations is mechanistically more complex. Thus, the catalyst reactivity depends on the ligand, the transition metal itself, and the initiating organic halide [4]. So far, copper-based systems seem to be the most efficient [5] when compared to other transition metals such as iron [6], nicke [7], ruthenium
[8], rhodium [9]. The counterions are often chloride and bromide, and bromide normally yields higher rates [10].

The majority of studies on living radical polymerization focuses either on hopolymerization or copolymerization [11]. Some works focus on statistical copolymerizations and it is a common practice to evaluate the monomer reactivity ratios of the living radical copolymerization system, and compare the results with the free radical copolymerization analogue [12]. The finding that the reactivity ratios for monomers under living free radical conditions are essentially the same as under normal free radical conditions is also fundamentally important. Thus, random copolymers prepared by living free radical processes are different on a molecular level

*Corresponding author, e-mail: kdemirelli@ firat.edu.tr

(c) BME-PT and GTE 
to those prepared by normal free radical methods, even though they may appear the same on the macroscopic level [13]. There have been several reports on monomer reactivity ratios in ATRP and other transition-metal mediated polymerizations $[14,15]$. This study was extended to a series of PCMMA in order to investigate the effect of the increasing molecular weight on monomer reactivity. Similar results were seen as for the amino methacrylates, with higher levels of incorporation into the copolymer in transition metal mediated polymerizations than in free radical polymerizations for all molecular weights [16].

In this work, our investigation concentrates on both the living radical copolymerization and conventional free radical copolymerization of phenoxycarbonylmethyl methacrylate (PCMMA) and styrene (St), the characterization of the resulting copolymers and their the monomer reactivity ratios were determined by both the Kelen-Tüdôs and FinemanRoss procedures. The glass transition and the degradation temperature, and average-molecular weights of copolymers were determined by differential scanning calorimetry (DSC), thermogravimetric analysis (TGA) and Gel Permeation Chromatography (GPC) measurements, respectively. Thermal analysis results are given for comparison purpose with each other for all polymers. Blends of poly(PCMMA) and poly(St) obtained via ATRP method are characterized by differential scanning calorimetry.

\section{Experimental}

\subsection{Materials}

Styrene (St) (Aldrich) were distilled under vacuum after washing with 5\% $\mathrm{NaOH}$ aqueous solution just before copolymerization. Cuprous(I)bromide/ $\mathrm{N}, \mathrm{N}, \mathrm{N}$ ',N",N"-pentamethyldiethyltriamine and ethyl 2-bromoacetate as initiator were used as received and phenoxycarbonylmethyl methacrylate was synthesized in our laboratory.

\subsection{Synthesis of phenoxycarbonylmethyl methacrylate (PCMMA)}

Phenoxycarbonylmethyl methacrylate was synthesized by the reaction of phenoxycarbonyl bromomethane with sodium methacrylate by using triethylbenzylammonium chloride (TEBAC)
(Aldrich) as a phase transfer catalyst and distilled under vacuum (bp: $162^{\circ} \mathrm{C}$ at $5 \mathrm{mmHg}$ ), yield: $72 \%$. IR $\left(\mathrm{cm}^{-1}\right.$, the most characteristic bands): 1784 $(\mathrm{C}=\mathrm{O}$ stretch adjacent to phenoxy), $1730(\mathrm{C}=\mathrm{O}$ stretch), 1638 ( $\mathrm{C}=\mathrm{C}$ stretch in the vinyl group), $1592(\mathrm{C}=\mathrm{C}$ stretch in aromatic ring).

${ }^{1} \mathrm{H}-\mathrm{NMR}\left(\mathrm{CDCI}_{3}, \delta\right): 2.03(\mathrm{~s}, 3 \mathrm{H}), 5.72(\mathrm{~s}, 1 \mathrm{H})$, $6.29(\mathrm{~s}, 1 \mathrm{H}), 6.9-7.4$ (aromatic ring protons).

\subsection{Characterization techniques}

Infrared spectra were obtained on a Perkin Elmer Spectrum One FT-IR spectrometer. NMR spectra were recorded on a Jeol FX 90Q NMR spectrometer at room temperature in $\mathrm{CDCI}_{3}$. Thermogravimetric analysis (TGA) measurements were carried out under a nitrogen flow with a TGA-50 thermobalance at a heating rate of $10^{\circ} \mathrm{C} \cdot \mathrm{min}^{-1}$. Gel Permeation Chromatography (GPC) analyses were carried out using a high pressure liquid chromatography pump with Agilent 1100 system equipped with a vacuum degasser, a refractive index detector. The eluting solvent was tetrahydrofurane (THF), the flow rate was $1 \mathrm{ml} \cdot \mathrm{min}^{-1}$. Calibration was achieved with polystyrene.

\subsection{Atom transfer radical copolymerization of PCMMA with St}

The general procedure for the copolymerization of PCMMA with St of six compositions was as follows: In all cases, predetermined amounts of monomers, ethyl 2-bromoacetate as initiator, $\mathrm{N}, \mathrm{N}, \mathrm{N}$ ',N",N"-pentamethyldiethyltriamine as ligand and the calculated amount of $\mathrm{CuBr}$ as catalyst were added to a flask. The mixture was first degassed three times and sealed in vacuo. The flask was shaked until the mixture was dissolved, immersed in an oil bath, and heated to the required temperature (at $110^{\circ} \mathrm{C}$ ). After a given time, the flasks were openned and dichloromethane was added to the sample to dissolve the copolymer. The heterogeneous solution was filtered. The copolymers were isolated by precipitation in ethylalcohol and dried under vacuum at $40^{\circ} \mathrm{C}$ for $24 \mathrm{~h}$. The conversion of the copolymerization was under $15 \%$. 


\subsection{Conventional Free-radical copolymeriza- tion of PCMMA with St}

Six copolymers of PCMMA with St were prepared in 1,4-dioxane at $60^{\circ} \mathrm{C}$ in the presence of AIBN. Predetermined amounts of the monomers, AIBN and the solvent were mixed in a polymerization tube. The mixture was degassed about 10 minute with argon and kept in a thermostatted oil bath at $60^{\circ} \mathrm{C}$. After desired time, the mixture was cooled to ambient temperature. The copolymers were precipitated into excess ethanol and purified by reprecipitation, and then the copolymers were dried under vacuum at 40 for $24 \mathrm{~h}$.

\subsection{Preparation of polymer blends}

Blend samples of Poly(PCMMA) $\left(M_{n}=50000\right)$ and poly $(\mathrm{St})\left(M_{n}=32000\right)$ - prepared under conditions above mentioned via ATRP method - were prepared by solution casting from dichloromethane at room temperature, and the blends were dried at $40^{\circ} \mathrm{C}$ for $24 \mathrm{~h}$ under vacuum.

\section{Results and discussion}

\subsection{Characterization of polymers}

The ${ }^{1} \mathrm{H}-\mathrm{NMR}$ spectrum of poly(PCMMA-co-St) showed signals at $4,62 \mathrm{ppm}\left(\mathrm{OCH}_{2} \mathrm{CO}, 2 \mathrm{H}\right)$ and $6,7-7,35 \mathrm{ppm}$ (aromatic ring protons, 10H) in PCMMA and St units. While the PCMMA units in the copolymer increase from 13 to $73 \%$ for copolymer prepared via ATRP, from 12 to $76 \%$ for copolymer prepared via conventional free radical polymerization. The FT-IR spectra of the copolymers prepared by conventional free radical polymerization in various feed ratios of PCMMA and $\mathrm{St}$ is illustrated in Figure 1. The FT-IR spectra for

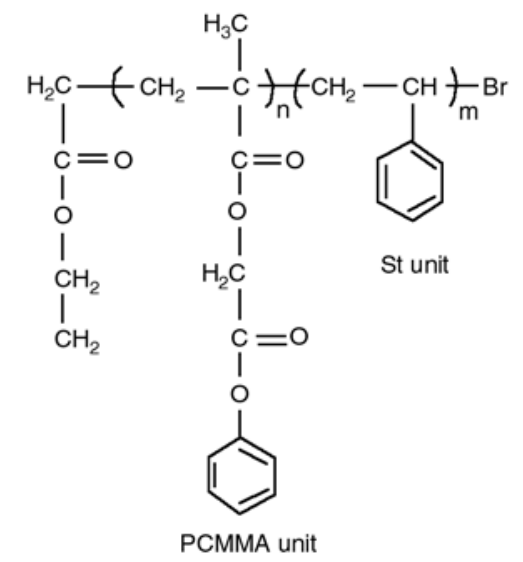

Figure 1. The structure of PCMMA and St copolymer

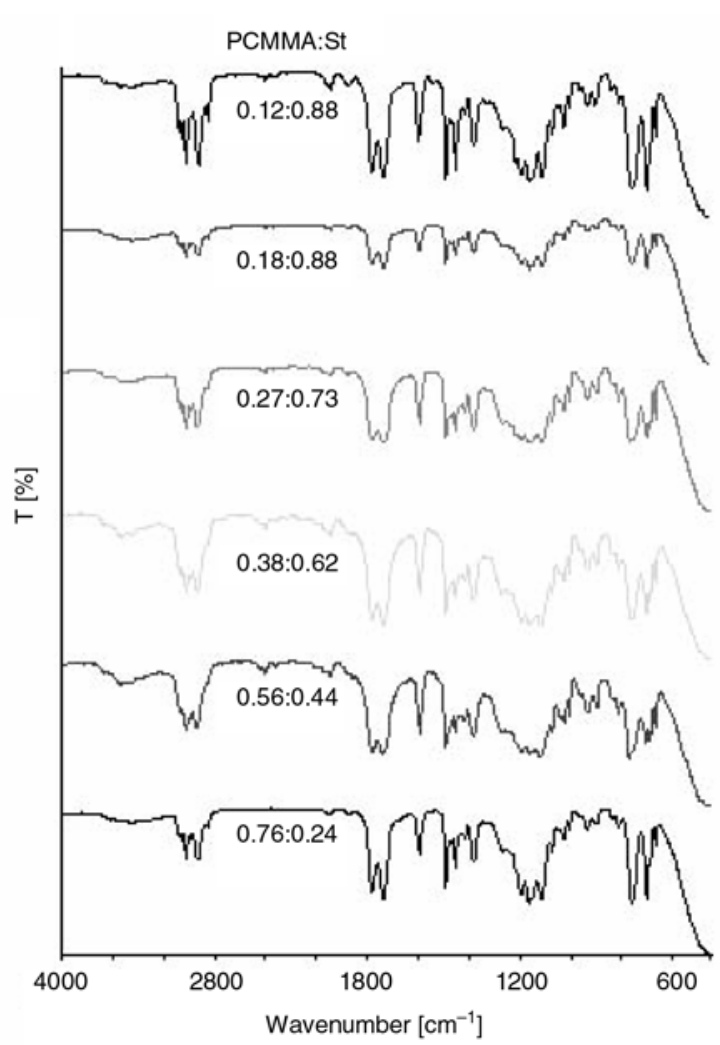

Figure 2. FT-IR spectra of PCMMA-St copolymer system

copolymers both Atom Transfer Radical and conventional free radical polymerizations showed two ester carbonyl bands at 1781 and $1736 \mathrm{~cm}^{-1}$, respectively. Also, ${ }^{13} \mathrm{C}-\mathrm{NMR}$ spectrum showed the signals attributed to $-\mathrm{CH}-$ of the $\mathrm{St}$ unit at $45.6 \mathrm{ppm}$ and the $-\mathrm{CH}_{2}$, which is adjacent to ester oxygene in PCMMA unit at $60.0 \mathrm{ppm}$. The other signals are in a good agreement with structure of copolymer showed in Figure 2.

\subsection{Atom transfer random copolymerization of PCMMA and $\mathbf{S t}$}

The copolymerization of six compositions with PCMMA and St was carried out in presence of Cuprous(I)bromide/N,N,N',N",N"'-pentamethyldiethyltriamine as catalyst system and ethyl 2-bromoacetate as initiator at $110^{\circ} \mathrm{C}$. The average-number molecular weights and polydispersities were determined by GPC. The decrease in $M_{n}$ values with an increasing molar fraction of PCMMA in the copolymer is propably due to manipulating by the controlled polymerization conversion of $\mathrm{St}$ units. In addition, as PCMMA unit increased in the resulting copolymers, $\mathrm{PD}\left(M_{w} / M_{n}\right)$ was increased $\left(1.48<M_{w} / M_{n}<1.92\right)$. On the other hand, $\mathrm{PD}\left(M_{w} / M_{n}\right)$ for the conventional free radical polymerization 
Table 1. GPC results in copolymers prepared via ATRP

\begin{tabular}{|l|c|c|}
\hline \multicolumn{1}{|c|}{ Entry } & $\mathbf{M}_{\mathbf{n}}$ & $\mathbf{M}_{\boldsymbol{w}} / \mathbf{M}_{\mathbf{n}}$ \\
\hline Poly(PCMMA0.12-co-St) & 20300 & 1.48 \\
\hline Poly(PCMMA0.27-co-St) & 39900 & 1.92 \\
\hline Poly(PCMMA0.77-co-St) & 49800 & 1.91 \\
\hline
\end{tabular}

Table 2. GPC results in copolymers prepared via conventional free radical polymerization

\begin{tabular}{|l|c|c|}
\hline \multicolumn{1}{|c|}{ Entry } & $\mathbf{M}_{\mathbf{n}}$ & $\mathbf{M}_{\mathbf{w}} / \mathbf{M}_{\mathbf{n}}$ \\
\hline Poly(PCMMA0.13-co-St) & 35800 & 1.64 \\
\hline Poly(PCMMA0.18-co-St) & 36300 & 1.72 \\
\hline Poly(PCMMA0.27-co-St) & 40500 & 1.76 \\
\hline Poly(PCMMA0.38-co-St) & 43300 & 1.87 \\
\hline
\end{tabular}

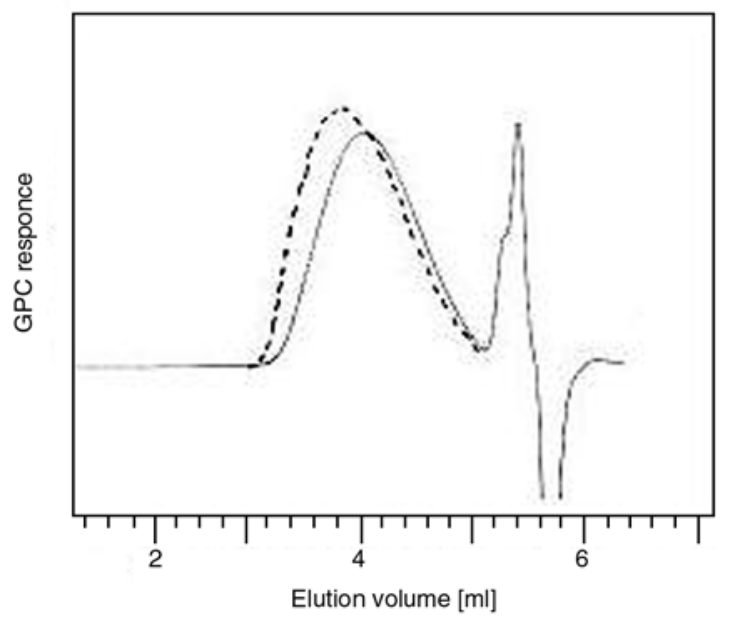

Figure 3. GPC curves of poly(PCMMA-co-St) in two various composition prepared by CFRP method [(poly(PCMMA0.12-co-St) Continous line, $\left.M_{w} / M_{n}=35000, \mathrm{PD}=1.64\right)$, (poly(PCMMA0.38-co-St), the dashed line, $\left.\left.M_{w} / M_{n}=43300, \mathrm{PD}=1.87\right)\right]$

was $1.64<M_{w} / M_{n}<1.87$. This sugests that the contribution of chain breaking and transfer as well as termination reactions during copolymerization can be neglected until a higher polymerization conversion, which is similar to the results reported by Zhou et al. [17]. The results are summarized in Table 1 and Table 2, respectively. The single GPC profiles of two resulting copolymers for the conventional free radical polymerization, and atom transfer radical polymerization are presented in Figure 3 and 4, respectively.

\subsection{Calculation of monomer reactivity ratios of PCMMA and $\mathrm{St}$}

Conventional free radical polymerization and the atom transfer radical random copolymerization of PCMMA and St initiated by ethyl 2-bromoacetate

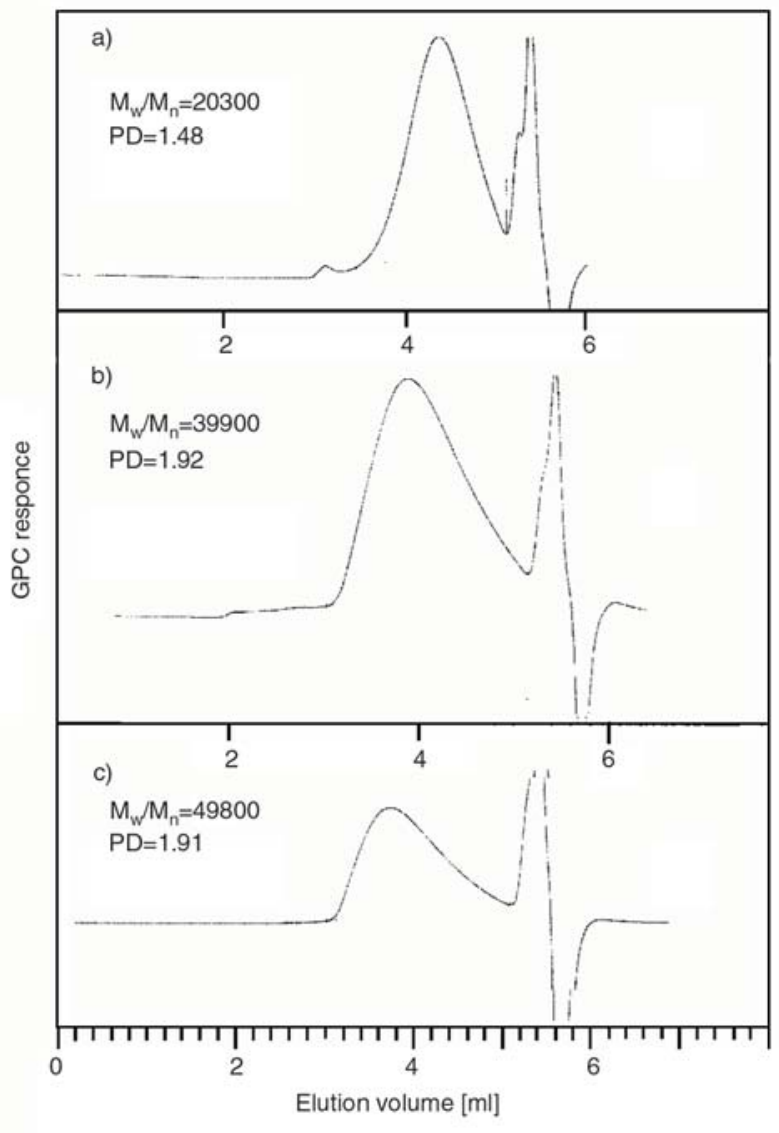

Figure 4. GPC curves of poly(PCMMA-co-St) in three different copolymer composition prepared by ATRP method

Table 3. Comonomer compositions in feed and copolymer via ATRPa and free radical polym

\begin{tabular}{|c|c|c|c|}
\hline Copolymers & $\begin{array}{c}\text { in feed } \\
\left(\mathbf{M}_{\mathbf{1}}\right)^{\mathbf{b}}\end{array}$ & $\begin{array}{c}\text { in copolymer via } \\
\mathbf{A T R P}\left(\mathbf{m}_{\mathbf{1}}\right)^{\mathbf{c}}\end{array}$ & $\begin{array}{c}\text { in copolymer via } \\
\mathbf{C F R P}\left(\mathbf{m}_{\mathbf{1}}\right)^{\mathbf{c}}\end{array}$ \\
\hline 1 & 0.10 & 0.13 & 0.12 \\
\hline 2 & 0.20 & 0.18 & 0.18 \\
\hline 3 & 0.35 & 0.33 & 0.27 \\
\hline 4 & 0.50 & 0.42 & 0.38 \\
\hline 5 & 0.70 & 0.48 & 0.56 \\
\hline 6 & 0.85 & 0.73 & 0.76 \\
\hline
\end{tabular}

a[Monomer]:[CuBr]:[Ligand]:[Initiator] $=100: 1: 2: 1$ at $110^{\circ} \mathrm{C}$ $\mathrm{M}_{1}^{\mathrm{b}}$ - mole fraction of PCMMA in feed,

$\mathrm{m}_{1}^{\mathrm{c}}$ - mole fraction of PCMMA in copolymer

for various ratios of PCMMA to St has been carried out. Chemoselectivity of PCMMA and St radicals generated in ATRP and conventional free radical polymerization are compared by determining the monomer reactivity ratios. Table 3 shows the influence of the initial molar compositions of the comonomers on those of the comonomers in the copolymers, in both ATR copolymerization and conventional free radical copolymerization. ${ }^{1} \mathrm{H}$ NMR spectroscopy has been used extensively to 
evaluate the microstructure of styrene-metacrylate copolymers. The monomer sequence distribution of these copolymers was also calculated theorotically from the monomer reactivity ratios and compared with the experimental data obtained by ${ }^{1} \mathrm{H}-\mathrm{NMR}$ $[18,19]$. In this study, the copolymer compositions were also analyzed with ${ }^{1} \mathrm{H}-\mathrm{NMR}$ spectra. The peaks at 6.6-7.4 ppm correspond to the aromatic protons in PCMMA and St units, the signal centered at $4.7 \mathrm{ppm}$ is assigned to methylene protons, which is adjacent to oxygene in PCMMA units. The other signals at $1-2.2 \mathrm{ppm}$ are assigned to methylene and methyl in polymer main chain. Thus, the mole fractions of PCMMA and St in the copolymer were determined from the ratio of the integral intensities of aromatic protons of PCMMA in $6.8-7.4 \mathrm{ppm}$ and the methylene protons in PCMMA unit between at $4.7 \mathrm{ppm}$. The copolymer compositions for ATRP have been calculated from the Equation (1):

$C=\frac{\text { Integral intensities of aromatic protons (lar) }}{\text { Integral intensities of aliphatic protons (lalf) }}$

$$
=\frac{5}{2 m_{1}}
$$

where $m_{1}$ is mole fraction of PCMMA, and $m_{2}$ is that of St in copolymer.

Similar calculations have been also made for conventional free radical copolymerization. The K-T and F-R parameters were calculated, using data in
Table 3, for both the living radical copolymerization and conventional free radical copolymerization of PCMMA and St, and the results were summarized in Table 4 and Table 5, respectively. Plots of PCMMA mole fraction in feed $v s$. PCMMA mole fraction in copolymers, synthesized by ATRP and CFRP, are shown in Figure 5. These plots exhibit azeotropic points at 0.22 for both CFRP and ATRP. One of the aims of this work was to determine whether the observed difference in monomer reactivity ratios could be due to monomer coordination to the transition metal used in transition-metal mediated polymerization. It is well known that monomer reactivity ratios can offer the message of

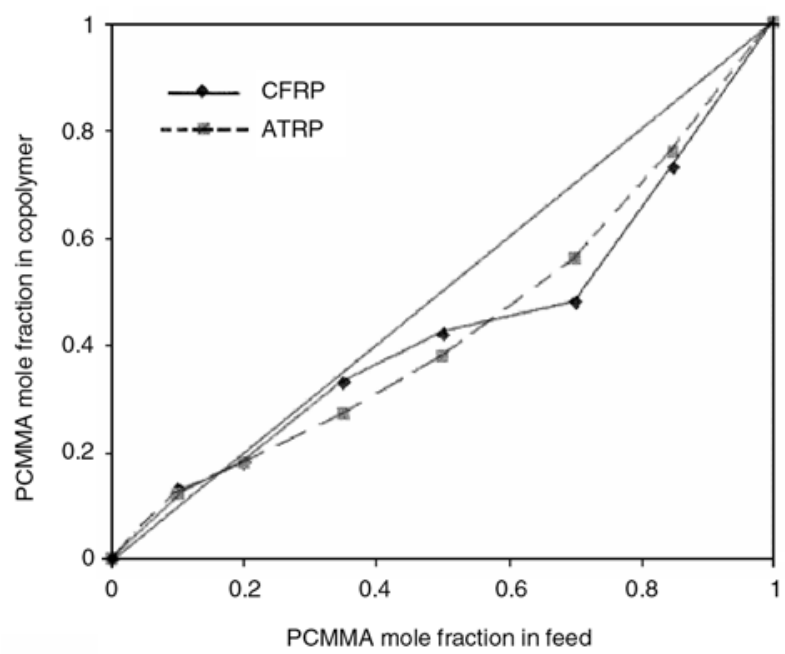

Figure 5. Composition diagrams of ATRP and conventional free radical copolymerization methods

Table 4. Results of the living radical copolymerization of PCMMA and St

\begin{tabular}{|c|c|c|c|c|c|c|}
\hline Sample No & $\mathbf{F}=\mathbf{M}_{\mathbf{1}} / \mathbf{M}_{\mathbf{2}}$ & $\mathbf{f}=\mathbf{m}_{\mathbf{1}} / \mathbf{m}_{\mathbf{2}}$ & $\mathbf{G}=\mathbf{F}(\mathbf{f} \mathbf{- 1}) / \mathbf{f}$ & $\mathbf{H}=\mathbf{F}^{2} / \mathbf{f}$ & $\boldsymbol{\eta}=\mathbf{G} / \boldsymbol{\alpha}+\mathbf{H}$ & $\boldsymbol{\xi}=\mathbf{H} / \boldsymbol{\alpha}+\mathbf{H}$ \\
\hline 1 & 0.111 & 0.149 & -0.633 & 0.082 & -0.592 & 0.076 \\
\hline 2 & 0.250 & 0.219 & -0.891 & 0.285 & -0.700 & 0.224 \\
\hline 3 & 0.538 & 0.492 & -0.555 & 0.588 & -0.352 & 0.373 \\
\hline 4 & 1.000 & 0.724 & -0.381 & 1.381 & -0.160 & 0.583 \\
\hline 5 & 2.333 & 0.923 & -0.194 & 5.896 & -0.028 & 0.856 \\
\hline 6 & 5.666 & 2.700 & 3.567 & 11.890 & 0.277 & 0.923 \\
\hline
\end{tabular}

$M_{1}$ - mole fraction of PCMMA in feed, $M_{2}$ - mole fraction of St in feed, $m_{1}$ - mole fraction of PCMMA in copolymer,

$m_{2}-$ mole fraction of St in copolymer. $\left(H_{\min } \cdot H_{\max }\right)^{1 / 2}=0.987 ; H_{\min }$ - lowest value of $H, H_{\max }$ - highest value of $H$

Table 5. Results of the conventional free radical copolymerization of PCMMA and St

\begin{tabular}{|c|c|c|c|c|c|c|}
\hline Sample No & $\mathbf{F}=\mathbf{M}_{\mathbf{1}} / \mathbf{M}_{\mathbf{2}}$ & $\mathbf{f}=\mathbf{m}_{\mathbf{1}} / \mathbf{m}_{\mathbf{2}}$ & $\mathbf{G}=\mathbf{F}(\mathbf{f}-\mathbf{1}) / \mathbf{f}$ & $\mathbf{H}=\mathbf{F} / \mathbf{f}$ & $\boldsymbol{\eta}=\mathbf{G} / \boldsymbol{\alpha}+\mathbf{H}$ & $\boldsymbol{\xi}=\mathbf{H} / \boldsymbol{\alpha}+\mathbf{H}$ \\
\hline 1 & 0.111 & 0.136 & -0.705 & 0.090 & -0.674 & 0.086 \\
\hline 2 & 0.250 & 0.219 & -0.891 & 0.285 & -0.718 & 0.229 \\
\hline 3 & 0.538 & 0.369 & -0.919 & 0.784 & -0.528 & 0.450 \\
\hline 4 & 1.000 & 0.612 & -0.633 & 1.633 & -0.244 & 0.630 \\
\hline 5 & 2.333 & 1.272 & 0.506 & 4.279 & 0.096 & 0.817 \\
\hline 6 & 5.666 & 3.166 & 3.876 & 10.140 & 0.349 & 0.913 \\
\hline
\end{tabular}

$M_{1}$ - mole fraction of PCMMA in feed, $M_{2}$ - mole fraction of St in feed, $m_{1}$ - mole fraction of PCMMA in copolymer,

$m_{2}$ - mole fraction of St in copolymer. $\left(H_{\min } \cdot H_{\max }\right)^{1 / 2}=0.955 ; H_{\min }$ - lowest value of $H, H_{\max }$ - highest value of $H$ 
Table 6. Monomer reactivity ratios of PCMMA-St monomer pair in ATRP and CFRP methods

\begin{tabular}{|l|c|c|c|c|}
\hline \multicolumn{1}{|c|}{ System } & Methods & $\mathbf{r}_{\mathbf{1}} \mathbf{a}^{\mathbf{a}}$ & $\mathbf{r}_{\mathbf{2}}$ & $\mathbf{r}_{\mathbf{1}} \cdot \mathbf{r}_{\mathbf{2}}$ \\
\hline \multirow{2}{*}{$\begin{array}{l}\text { Atom transfer radical } \\
\text { polymerization }\end{array}$} & $\mathrm{K}-\mathrm{T}$ & 0.24 & 0.76 & 0.18 \\
\cline { 2 - 5 } $\begin{array}{l}\text { Conventional Free radical } \\
\text { polymerization }\end{array}$ & $\mathrm{F}-\mathrm{R}$ & 0.33 & 0.96 & 0.31 \\
\cline { 2 - 5 } & $\mathrm{K}-\mathrm{T}$ & 0.32 & 0.90 & 0.28 \\
\hline
\end{tabular}

${ }^{a} \mathrm{r}_{1}$ - monomer reactivity ratio of PCMMA

relative reactivity of comonomers [20-22]. To estimate the relative reactivity of PCMMA and St in the atom transfer radical polymerization and conventional free radical polymerization, the KelenTüdôs [23] and Fineman-Ross [24] equations were used, which are $\eta=\left(r_{1}+r_{2} / \alpha\right) \xi-r_{2} / \alpha$ and $G=$ $r_{1} H-r_{2}$, respectively (Notations in the equations have been described in Table 4 or 5). The plots of $G$ versus $H$ and $\eta$ versus $\xi$ for both systems were obtained, respectively. From the slope and intercept of the straight line, the monomer reactivity ratios of PCMMA and St were determined and given in Table 6. Monomer reactivity ratios of PCMMA and St is signifficantly lower than those for ATR and CFR polymerizations by both methods. The results show that the copolymers possess a predominantly random structure in a wide range of monomer feeds.

Apparently, the values of monomer reactivity ratios indicate that the growing radicals with PCMMA end were not added at a nearly same rate to PCMMA or St monomers. The $r_{2}$ according to K-T and F-R methods shows that the styrene monomer is more reactive than PCMMA toward the poly(PCMMA) radical. Initially, the copolymer sequence will be made richer by the St units and the arrangement will be statistical. The $r_{1}$ and $r_{2}$ values obtained via both polymerization methods are the similar to that of n-octyl acrylate-styrene copolymer system [25]. For the ATR copolymerization were evaluated through plots of the copolymer compositions $\left(m_{1}\right)$ measured from ${ }^{1} \mathrm{H}-\mathrm{NMR}$ as the molar fraction of PCMMA versus the feed compositions measured as the molar fraction of PCMMA $\left(M_{1}\right)$. The copolymerization experiments were carried out at different temperatures. It is seen that compositions of copolymers obtained by the two copolymerization techniques are somewhat different from each other. But it can be suggested that random copolymers prepared by living free radical processes are different on a molecular level from those prepared by normal free radical methods. This can be ascribed not to the different nature of the propagating species but to the difference in the time scale of monomer addition or other factors. Thus, in the studies done on copper catalyzed copolymerization of n-alkylmethacrylate and styrene $[26,27]$, no signifficant differences were observed in monomer reactivity ratio as well as in monomer sequence between the copper-catalyzed and conventional radical polymerization techniques. The two monomers have a strong tendency to form random copolymer because the value of $r_{1} \cdot r_{2}$ is between 0 and 1 . For living radical systems all chains are initiated at the same time and grow at approximately the same rate, in the case or conventional free radical polymerization, continous initiation leads to chains initiating and terminating at different stages of the polymerization [28].

\subsection{Differential scanning calorimetry (DSC) measurements}

The glass transition temperatures of the copolymers of PCMMA and St prepared by ATRP and conventional free radical polymerization were measured by DSC. Representative DSC curves of the copolymers heated at $20^{\circ} \mathrm{C} / \mathrm{min}$ to $200^{\circ} \mathrm{C}$ were showed in Figure 6 and 7, respectively. The $T_{g}$ values of poly(PCMMA) and poly(St) were measured as 80 and $103^{\circ} \mathrm{C}$, respectively. The unique transition observed for PCMMA-St copolymer system prepared by CFRP and ATRP methods corresponds to

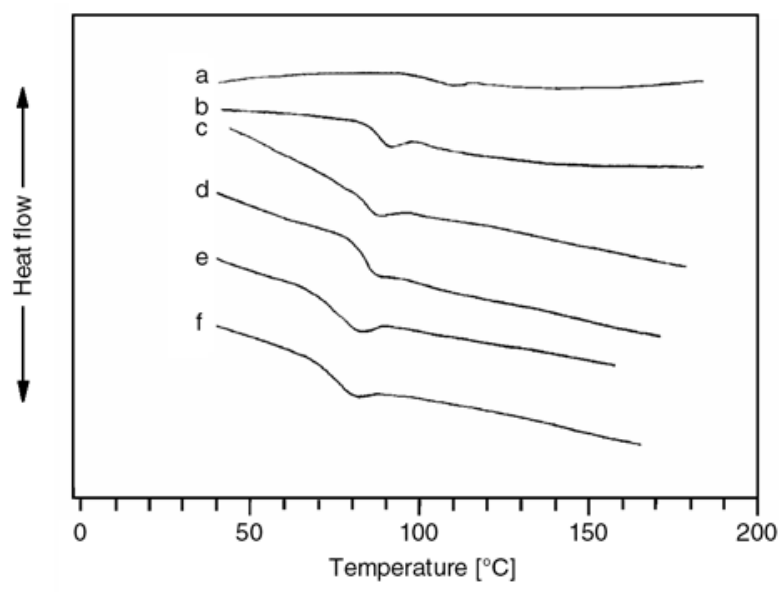

Figure 6. Differential scanning calorimeter (DSC) curves of phenoxycarbonyl methyl metahcrylate and styrene copolymer system prepared by conventional radical polymerization method. PCMMA unit in copolymer prepared by CFRP; a: 0.13 , b: 0.18, c: 0.33 , d: 0.42 , e: 0.48 , f: 0.73 . 


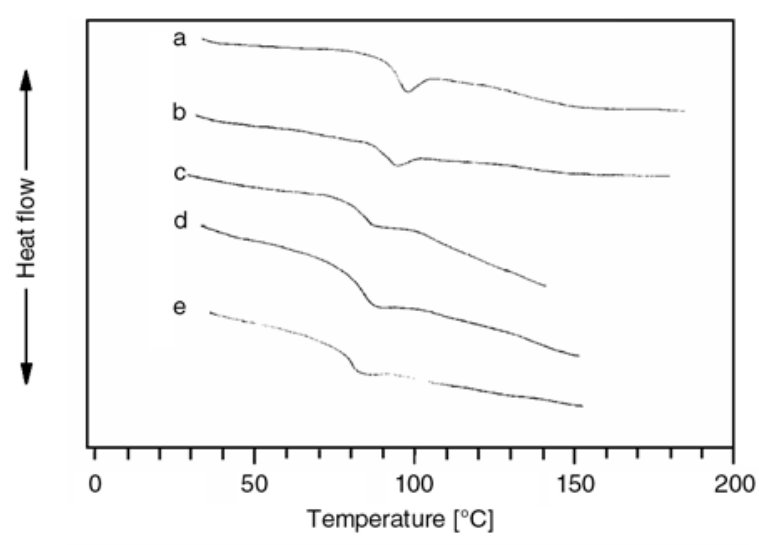

Figure 7. Differential scanning calorimetry (DSC) curves of phenoxycarbonyl methyl metahcrylate and styrene copolymer system prepared by atom transfer radical polymerization method. PCMMA unit in copolymer prepared by ATRP; a: 0.12 , b: 0.18 , c: 0.38 , d: 0.56 , e: 0.76 .

Table 7. Characterization of PCMMA and St copolymers

\begin{tabular}{|c|c|c|c|c|}
\hline Entry & $\left(_{\left(\mathbf{m}_{\mathbf{1}}\right)^{\mathbf{a}}}\right.$ & ${\left(\mathbf{m}_{\mathbf{1}}\right)^{\mathbf{b}}}$ & $\begin{array}{c}\mathbf{T}_{\mathbf{g}}\left[{ }^{\circ} \mathbf{C}\right] \\
(\mathbf{b y} \mathbf{A T R P})\end{array}$ & $\begin{array}{c}\mathbf{T}_{\mathbf{g}}\left[{ }^{\circ} \mathbf{C}\right] \\
(\mathbf{b y} \mathbf{C F R P})\end{array}$ \\
\hline 1 & 0.13 & 0.12 & 101 & 96 \\
\hline 2 & 0.18 & 0.18 & 88 & 92 \\
\hline 3 & 0.33 & 0.27 & 84 & 88 \\
\hline 4 & 0.42 & 0.38 & 82 & 85 \\
\hline 5 & 0.48 & 0.56 & 77 & - \\
\hline 6 & 0.73 & 0.76 & 75 & 79 \\
\hline
\end{tabular}

$m_{1}{ }^{a}$ - PCMMA unit in copolymer prepared by ATRP;

$m_{1}{ }^{\mathrm{b}}-$ PCMMA unit in copolymer by CFRP

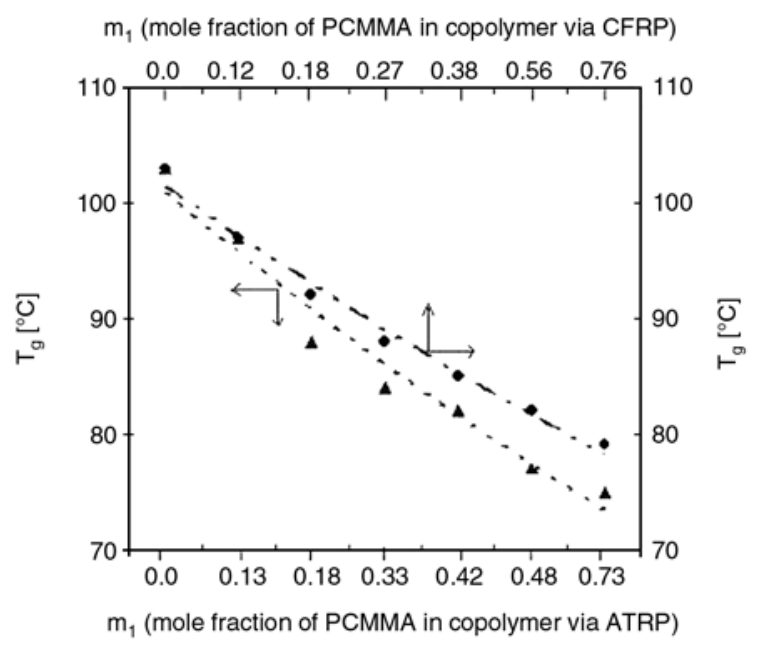

Figure 8. Plots of the $T_{g}$ of a series of PCMMA-St copolymers as a function of PCMMA mole fraction in the copolymer prepared by ATRP and conventional radical polymerization methods

the glass transition of the soft PCMMA segments and appears at higher temperatures. The feature may be attributed to miscibility of both types of

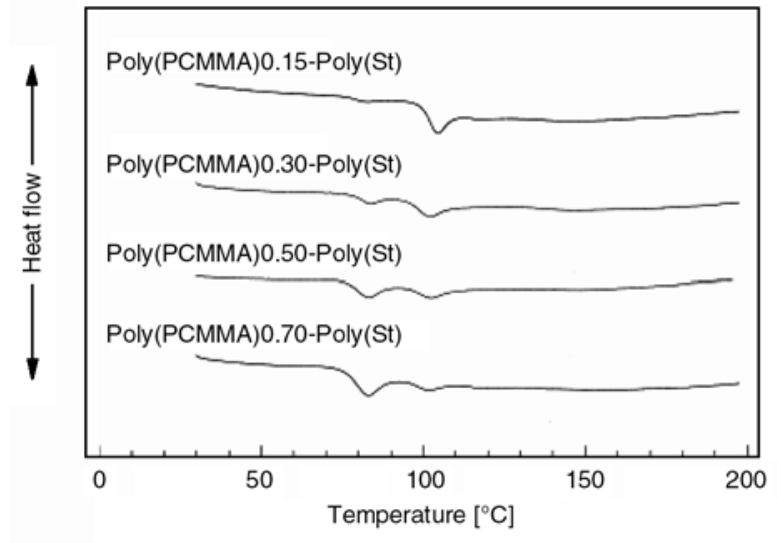

Figure 9. DSC traces of blend polymers heated at $20^{\circ} \mathrm{C} / \mathrm{min}$ to $200^{\circ} \mathrm{C}$

segments. The $T_{g}$ 's of all the copolymers synthesized by CFRP and ATRP methods are also collected in Table 7. The glass transition temperatures of copolymers measured by depending on an increase of the PCMMA unit are between 75$101^{\circ} \mathrm{C}$ and $79-96^{\circ} \mathrm{C}$, respectively. The plots of the $T_{g}$ values versus mole fraction of PCMMA in the copolymers is shown in Figure 8. The observed $T_{g}$ 's of the copolymers indicate a slightly negative deviation with respect to linearity that can be associated with a slightly lower free volume.

The glass transition temperatures were measured to analyze the phase behavior of poly(PCMMA) and poly $(\mathrm{St})$ homopolymers. The existence of one or more glass transition temperatures is important for discussing whether or not a miscible or immiscible presents one or more phase. It is known that an immiscible blend shows glass transition temperature of each individual polymer, but a miscible blend has only one glass transition temperature. DSC curves of polymer blends prepared in various ratios for comparison purpose were showed in Figure 9. Each polymer blend prepared in this study showed two separate $T_{g}$ 's, which can be attributed to poly(PCMMA) and poly(St) to give the incompatible blends. While poly(PCMMA), which is one of polymers contains polar ester and apolar alkyl groups, poly(St) contains apolar group. This means that it does not indicate similar kinds of interactions between both polymers. But, most of polymers having these kinds of properties are generally incompatible [29]. 


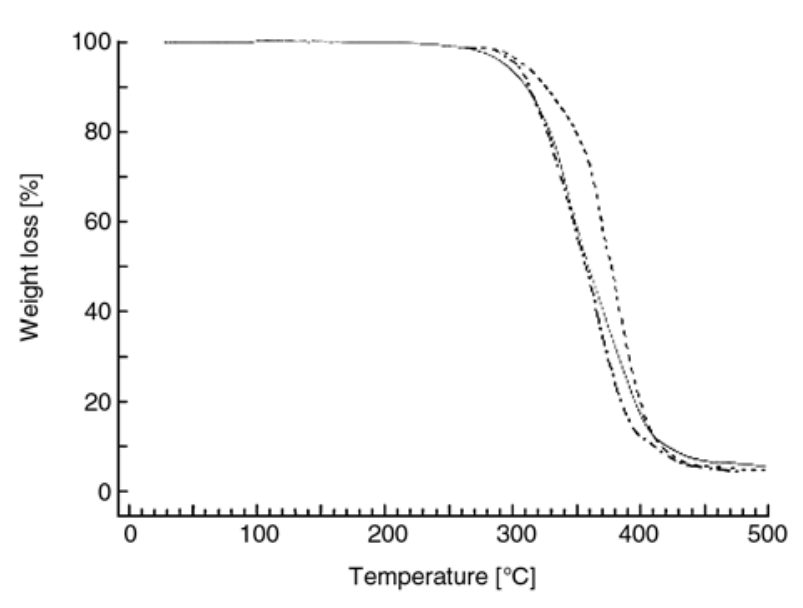

Figure 10. TGA curves of the polymers (heating rate under $\mathrm{N}_{2}$ flow at $10^{\circ} \mathrm{C} / \mathrm{min}$ )

\subsection{Thermogravimetric study}

The some of thermogravimetric curves obtained from room temperature to $500^{\circ} \mathrm{C}$ at a heating rate of $10^{\circ} \mathrm{C} / \mathrm{min}$ under nitrogen flow for poly (PCMMA-co-St), and poly(PCMMA)s prepared by ATRP and conventional free radical polymerization were given in Figure 10 for comparison. The decomposition of poly(PCMMA) proceeds in two steps, the first of which is at $270^{\circ} \mathrm{C}$. The second stage, that is, more rapid weigth loss is attributed to the degradation reaction by either the side chain decomposition or the random chain scission in the backbone. That of polystyrene synthesized by conventional free radical polymerization occurs in only one step. Also, poly(PCMMA), is more stable thermally than poly(PCMMA) prepared by free radical initiator. The temperatures at which weight loss begins for the PCMMA-St copolymers are somewhat lower than that of poly(St). The thermal stability of copolymer increases with the increasing styrene unit content in the copolymer system. TGA results of the polymers are summarized in Table 8 .
When poly(PCMMA) was heated to $270^{\circ} \mathrm{C}$, and then to $320^{\circ} \mathrm{C}$, the residual polymer was completely dissolved in most of solvents such as tetrahydrofuran, methylenechloride, chloroform, acetonitrile, 1,4-dioxane and dimethylsulphoxide. This means that poly(PCMMA) heated at least to $320^{\circ} \mathrm{C}$ is not crosslinked. Thus, during degradation of poly (PCMMA) rupture of an allylic carbon-carbon bond forms two radicals, one tertiary and the other a resonance stabilized allylic radical. Then decomposition of poly(PCMMA) continues by elimination of monomer, the driving force being formation of tertiary radical. The average molecular weight decreased from 50000 to 39000 . This means that decreases 50 PCMMA units from poly(PCMMA) chain. The residue of poly(PCMMA) heated to $380^{\circ} \mathrm{C}$ was not dissolved in any solvent. Average molecular weights of residue for polymer heated to $270^{\circ} \mathrm{C}$ and $320^{\circ} \mathrm{C}$ were characterized by GPC. They were illustrated in Figure 11. Although average molecular weight of residues decrease when heated from room temperature to $320^{\circ} \mathrm{C}$, polydispersities were expanded considerably from 1.91 to 3.01. This may be a result of elimination of monomer, the side group elimination or the random chain scission in the backbone during the degradation.

\section{Conclusions}

Phenoxycarbonylmethyl methacrylate (PCMMA) and styrene ( $\mathrm{St}$ ) were copolymerized by conventional polymerization at $60^{\circ} \mathrm{C}$ and atom transfer radical polymerization at $110^{\circ} \mathrm{C}$ in different ratios using AIBN and in the presence of ethyl 2-bromoacetate, cuprous(I)bromide $(\mathrm{CuBr})$, and N,N,N',N",N"-pentamethyldiethyltriamine, respectively. The monomer reactivity ratios were calculated from the feed composition and copolymer

Table 8. TGA data for the polymers prepared by ATRP and CFRP methods

\begin{tabular}{|c|c|c|c|c|c|}
\hline Polymers & $\begin{array}{c}\mathbf{T}^{\mathrm{a}}{ }_{\mathrm{i}} \\
{\left[{ }^{\circ} \mathbf{C}\right]}\end{array}$ & $\begin{array}{l}\mathrm{T} \% 50 \\
{\left[{ }^{\circ} \mathrm{C}\right]}\end{array}$ & $\begin{array}{c}\text { Weigth loss at } 300^{\circ} \mathrm{C} \\
{[\%]}\end{array}$ & $\begin{array}{c}\text { Weigth loss at } 350^{\circ} \mathrm{C} \\
{[\%]}\end{array}$ & $\begin{array}{c}\text { Weigth loss at } 400^{\circ} \mathrm{C} \\
{[\%]}\end{array}$ \\
\hline Poly(PCMMA) by ATRP & 270 & 312 & 3 & 34 & 83 \\
\hline Poly(PCMMA) by CFRP & 243 & 341 & 25 & 55 & 82 \\
\hline Poly(St) by CFRP & 310 & 392 & 0 & 9 & 67 \\
\hline Poly(PCMMA0.76-co-St) by CFRP & 280 & 356 & 4 & 43 & 88 \\
\hline Poly(PCMMA0.38-co-St) by CFRP & 272 & 371 & 3 & 27 & 81 \\
\hline Poly(PCMMA0.18-co-St) by CFRP & 275 & 375 & 4 & 20 & 80 \\
\hline Poly(PCMMA0.12-co-St) by CFRP & 270 & 379 & 4 & 25 & 82 \\
\hline Poly(PCMMA0.73-co-St) by ATRP & 275 & 360 & 6 & 43 & 82 \\
\hline Poly(PCMMA0.42-co-St) by ATRP & 291 & 365 & 2 & 28 & 86 \\
\hline
\end{tabular}

anitial decomposition temperature 


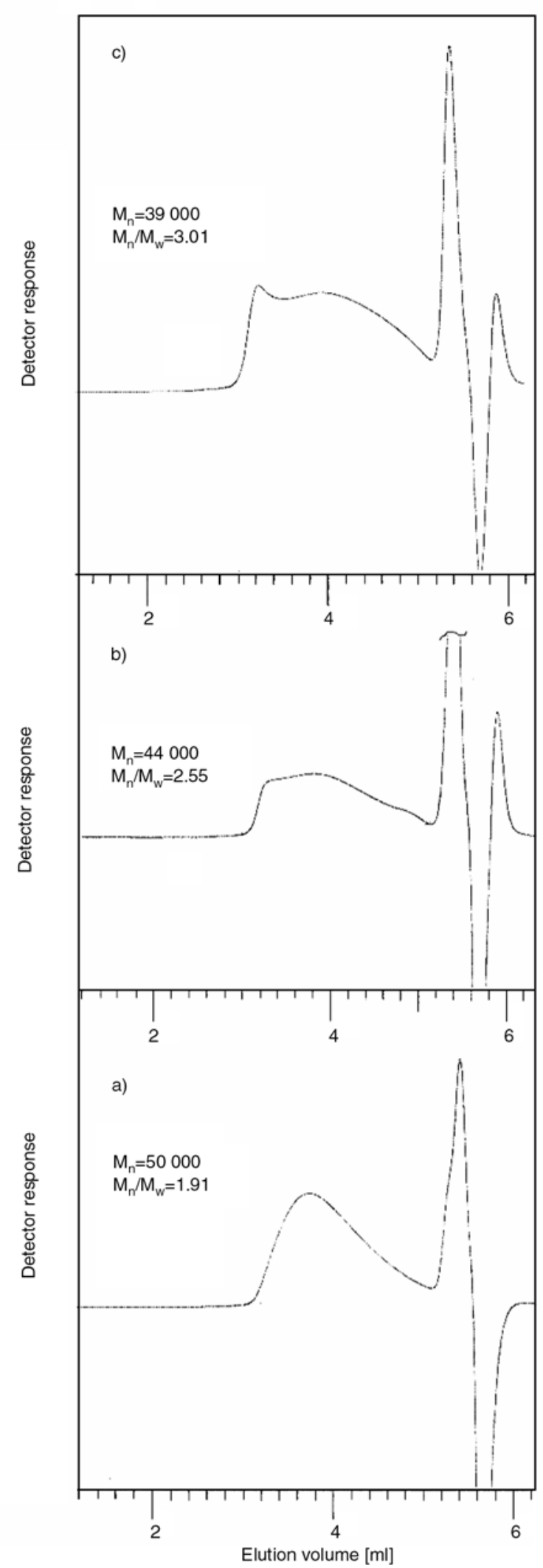

Figure 11. GPC curves of residue a) original poly(PCMMA), b) residue copolymer heated to $270^{\circ} \mathrm{C}$, and c) to $320^{\circ} \mathrm{C}$

composition determined by ${ }^{1} \mathrm{H}-\mathrm{NMR}$ spectroscopy. Their monomer reactivity ratios were determined by the K-T and F-R methods. In this copolymerization system, two monomers have a tendency to form alternatif copolymer. The monomer reactivity ratios of PCMMA-St monomers pair do not vary much $\left(r_{\mathrm{PCMMA}}=0.33 ; r_{\mathrm{St}}=0.96\right)$ by changing polymerization temperature and polymerization method i. e., ATRP and CFRP. The DSC curves of all the copolymers synthesized by CFRP and ATRP methods showed single transition. The glass transition temperatures of copolymers measured by depending on an increase of the PCMMA unit are between $75-101^{\circ} \mathrm{C}$ and $79-96^{\circ} \mathrm{C}$, respectively. In case of poly(PCMMA-co-St) prepared by CFRP and ATRP methods, initial decomposition temperature of copolymers increased with an increasing in $\mathrm{St}$ content. While poly(PCMMA) heated to $320^{\circ} \mathrm{C}$ was dissolved in various solvents, average molecular weight of residue polymer was decreased from 50000 to 39000 and polydispersity changed from 1.91 to 3.01. Each polymer blend prepared in this study showed two glass transitions, which can be attributed to the immiscibility of poly(PCMMA) and poly $(\mathrm{St})$ resulting in microphase separation.

\section{Acknowledgements}

The authors wish to thank the State Planning Organization, in Turkey, (DPT-2003).

\section{References}

[1] Webster O. W.: Living polymerization methods. Science, 251, 887-893 (1991).

[2] Abraham S., Ha C-S., Kim I.: Synthesis of poly (styrene-block-tert-butyl acrylate) star polymers by atom transfer radical polymerization and micellization of their hydrolyzed polymers. Journal of Polymer Science, Part A: Polymer Chemistry, 43, 6367-6378 (2005).

[3] Hawker C. J.: 'Living' free radical polymerization: A unique technique for the preparation of controlled macromolecular architectures. Accounts of Chemical Research, 30, 373-382 (1997).

[4] Kickelbick G., Reinöhl U., Ertel T. S., Betagnolli H., Matyjaszewski K.: The copper catalyst in atom-transfer radical polymerizations: Structural observations. Abstracts of Papers of the American Chemical Society, 768, 211-222 (1999).

[5] Queffelec J., Gaynor S. G., Matyjaszewski K.: Optimization of atom transfer radical polymerization using $\mathrm{Cu}(\mathrm{I}) /$ tris(2-(dimethylamino)ethyl)amine as a catalyst. Macromolecules, 33, 8629-8639 (2000). 
[6] Ando T., Kamigaito M., Sawamoto M.: Iron(II)chloride complex for living radical polymerization of methyl metacrylate. Macromolecules, 30, 4507-4510 (1997).

[7] Dubois P., Ropson N., Jerome R., Teyssie P.: Macromolecular engineering of polylactones and polylactides .19. Kinetics of ring-opening polymerization of $\varepsilon$-caprolactone initiated with functional aluminum alkoxides. Macromolecules, 29, 1965-1975 (1996).

[8] Kato M., Kamigato M., Sawamoto M., Higashimura T.: Polymerization of methyl-methacrylate with the carbon-tetrachloride dichlorotris (triphenylphosphine) ruthenium(Ii) methylaluminum bis(2,6-di-tert-butylphenoxide) initiating system- possibility of living radical polymerization. Macromolecules, 28, 1721-1723 (1995).

[9] Moineau G., Dubois P., Granel C., Jérome R., Senninger T., Teyssie P.: Alternative atom transfer radical polymerization for MMA using $\mathrm{FeCl}_{3}$ and $\mathrm{AIBN}$ in the presence of triphenylphosphine: An easy way to well-controlled PMMA. Macromolecules, 31, 545547 (1998)

[10] Fischer H.: The persistent radical effect: A principle for selective radical reactions and living radical polymerizations. Chemical Reviews, 101, 3581-3610 (2001)

[11] Matyjaszewski K., Ziegler M. J., Arehart S. V., Greszta D., Pakula T.: Gradient copolymers by atom transfer radical copolymerization. Journal of Physical Organic Chemistry, 13, 775-786 (2000).

[12] Ziegler M. J., Matyjaszewski K.: Atom transfer radical copolymerization of methyl methacrylate and nbutyl acrylate. Macromolecules, 34, 415-424 (2001).

[13] Hawker C. J., Bosman A. W., Harth E.: New polymer synthesis by nitroxide mediated living radical polymerizations. Chemical Reviews, 101, 3661-3688 (2001).

[14] Moineau G., Minet M., Dubois P., Teyssie P., Senninger T., Jérome R.: Controlled radical polymerization of (meth)acrylates by ATRP with $\mathrm{NiBr}_{2}(\mathrm{PPh} 3)(2)$ as catalyst. Macromolecules, 32, 27-35 (1999).

[15] Haddleton D. M., Crossman M. C., Hunt K. H., Topping C., Waterson C., Suddaby K. G.: Identifying the nature of the active species in the polymerization of methacrylates: Inhibition of methyl methacrylate homopolymerizations and reactivity ratios for copolymerization of methyl methacrylate n-butyl methacrylate in classical anionic, alkyllithium/trialkylaluminum-initiated, group transfer polymerization, atom transfer radical polymerization, catalytic chain transfer, and classical free radical polymerization. Macromolecules, 30, 3992-3998 (1997).

[16] Lad J., Harrison S., Haddleton D. M.: Mechanistic aspects of copper-mediated living radical polymerization. ACS Symposium Series, 854, 148-160 (2003).
[17] Zhou P., Chen G. Q., Hong H., Du F. S., Li Z. C., Li F. M.: Synthesis of C-60-end-bonded polymers with designed molecular weights and narrow molecular weight distributions via atom transfer radical polymerization. Macromolecules, 33, 1948-1954 (2000).

[18] Simionescu C. I., Barboiu V., Simionescu B. C., Talmaciu V., Sava C.: On the copolymerization model and microstructure of methyl acrylate- styrene radical copolymer- influence of $\mathrm{ZnCl}_{2}$. Journal of Polymer Science, Part A: Polymer Chemistry, 24, 851-860 (1986).

[19] Uebel J. J., Dinan F. J.: A reassessment of the H-1Nmr spectra of styrene methyl-methacrylate co-polymers. Journal of Polymer Science, Part A: Polymer Chemistry, 21, 2427-2438 (1983).

[20] Percec V., Barboiu B., Kim H-J.: Arenesulfonyl halides: An universal class of functional initiators for metal-catalyzed 'living' radical polymerization of styrene(s), methacrylates, and acrylates. Journal of the American Chemical Society, 120, 305-316 (1998).

[21] Shinoda H., Miller P. J., Matyjaszewski K.: Macromolecules, improving the structural control of graft copolymers by combining ATRP with the macromonomer method. Macromolecules, 34, 3186-3194 (2001).

[22] Yee L. H., Heuts J. P. A., Davis T. P.: Copolymerization propagation kinetics of dimethyl itaconate and styrene: Strong entropic contributions to the penultimate unit effect. Macromolecules, 34, 3581-3586 (2001).

[23] Tüdős F., Kelen T.: Analysis of linear methods for determining copolymerization reactivity ratios. 1 . New improved linear graphic method. Journal of Macromolecular Science, Part A: Chemistry, 9, 1-27 (1975).

[24] Fineman M., Ross S. D.: Linear method for determining monomer reactivity ratios in copolymerization. Journal of Polymer Science, 5, 259-262 (1950).

[25] Bisht H. S., Ray S. S., Chatterjee A. K.: Conventional and atom transfer radical copolymerization of $n$-octyl acrylate-styrene: Chemoselectivity and monomer sequence distribution by ${ }^{1} \mathrm{H}-\mathrm{NMR}$. European Polymer Journal, 39, 1413-1420 (2003).

[26] Arehart S. V., Matyjazewski K.: Atom transfer radical copolymerization of styrene and n-butyl acrylate. Macromolecules, 32, 2221-2231 (1999).

[27] Kamigaito M., Ando T., Sawamoto M.: Metal-catalyzed living radical polymerizaton. Chemical Reviews, 101, 3689-3746 (2001).

[28] Wang J-S., Matyjaszewski K.: Controlled living radical polymerization: Atom-transfer radical polymerization in the presence of transition-metal complexes. Journal of The American Chemical Society, 117, 5614-5615 (1995).

[29] Nolley E., Barlow J. W., Paul D. R.: Mechanical properties of polypropylene-low density polyethylene blends. Polymer Engineering and Science, 20, 364 369 (1980). 